\title{
Introducing the progesterone contraceptive vaginal ring in sub- Saharan Africa
}

Population Council

Follow this and additional works at: https://knowledgecommons.popcouncil.org/departments_sbsr-rh

Part of the Demography, Population, and Ecology Commons, Family, Life Course, and Society Commons, International Public Health Commons, and the Maternal and Child Health Commons How does access to this work benefit you? Let us know!

\section{Recommended Citation}

"Introducing the progesterone contraceptive vaginal ring in sub-Saharan Africa." New York: Population Council, 2016. 


\section{INTRODUCING THE PROGESTERONE CONTRACEPTIVE VAGINAL RING IN SUB-SAHARAN AFRICA}

Research supports the introduction of the Progesterone Vaginal Ring (PVR), a user-controlled method that helps breastfeeding women safely space or delay their next pregnancy.

In sub-Saharan Africa, particularly across Kenya, Nigeria, and Senegal, ongoing efforts are helping expand access to contraceptive methods for breastfeeding women. These efforts begin with basic research and development to bring innovations in family planning from bench to bedside, and continue with a deepening understanding of the intricacies of product introduction in underserved communities.

For the first six months after childbirth, exclusive breastfeeding provides effective contraception, but many women do not or are unable to breastfeed exclusively. Once a woman stops breastfeeding, begins adding other foods or liquids to her infant's diet, or starts menstruating again, she is at risk of becoming pregnant.

To bridge the gap between the demand for innovation and access to novel contraceptive options for breastfeeding women, the Population Council and its partners conducted three distinct Willingness to Pay research initiatives to estimate the effect of price on demand for the Progesterone Vaginal Ring (PVR) in sub-Saharan Africa, where unmet need is outpacing the ability to provide timely, cost-effective access to new methods.

Additionally, changes in the resource landscape have prompted governments to explore "Total Market" solutions. The Total Market Approach is defined as a coordinated approach that serves all clients in a country-from those requiring free or highly subsidized services to those who are willing and able to pay-to maximize access, equity, and sustainability and to direct scarce resources to sectors and users where need is not met. Using this as a guiding design principle, this research provides new insights on the amount consumers are willing to pay for the PVR from various service sectors-public, private nonprofit, and private commercial (Evidence Project 2014; Obare et al. 2014).

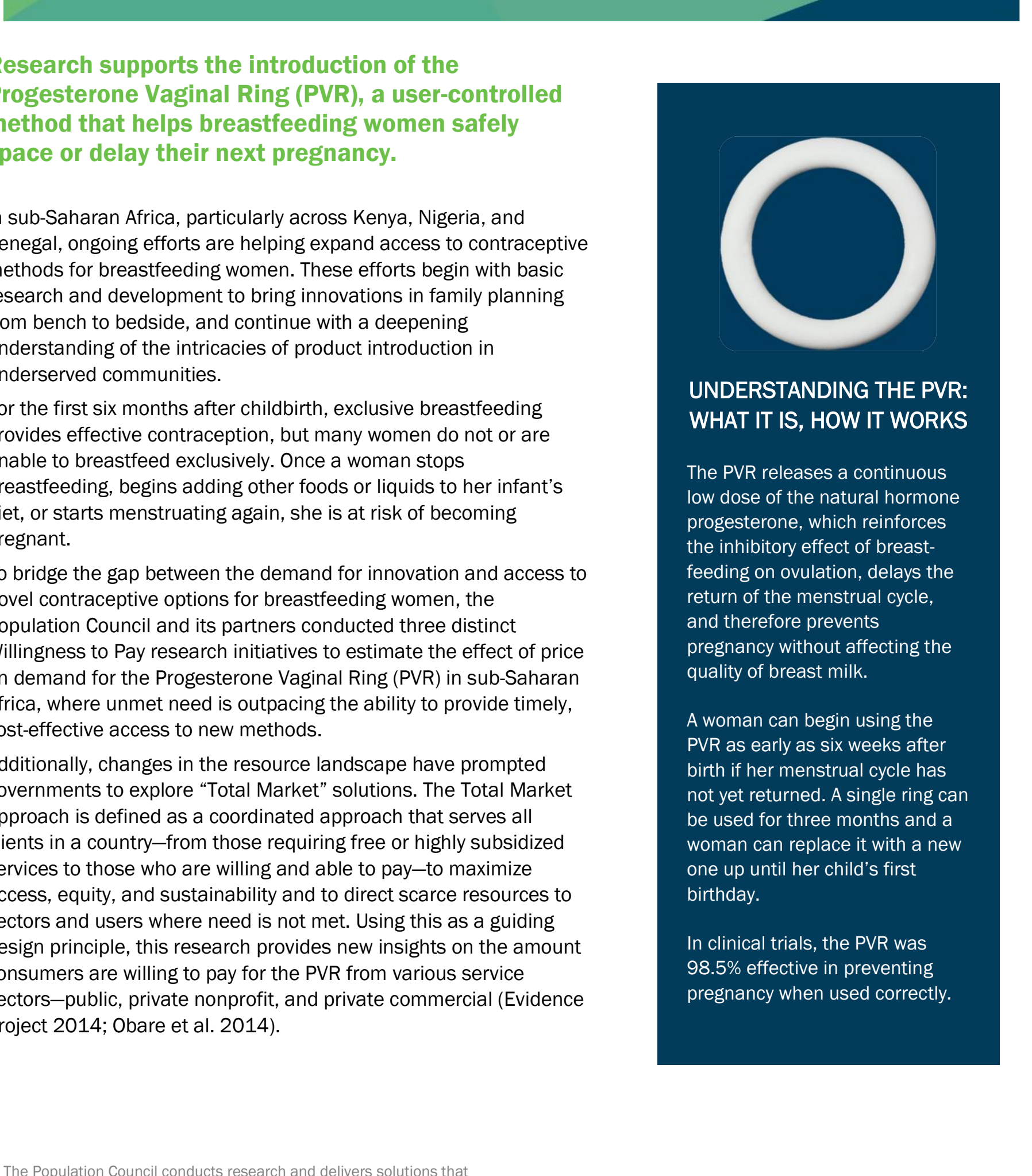

The Population Council conducts research and delivers solutions that improve lives around the world. Big ideas supported by evidence: It's our model for global change. popcouncil.org
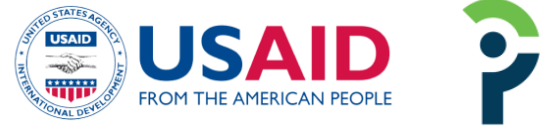

POPULATION COUNCIL

Ideas. Evidence. Impact. 


\section{RESEARCH AND KEY FINDINGS}

Within each country, the Council and partners sought to:

- Evaluate the willingness to pay for the PVR among women at health facilities in the public, private nonprofit, and private commercial sectors.

- Assess providers' willingness across public, private nonprofit, and private commercial sectors to counsel and offer the PVR to women.

- Understand the willingness to procure the PVR among suppliers (e.g., governments, donors).

Stakeholders noted consistent reasons supporting the willingness to pay, including provider recommendations of the PVR, wanting/liking the method, desire to prevent unintended pregnancy, and heightened interest in helping broaden access to the PVR for women.

Overall, although cost plays an important role in regulating consumer demand, women and their health care providers indicated that the desire to avoid unintended pregnancy and the need for access to modern contraception outweighed cost barriers as critical components that influence family planning decisionmaking. Provider interest in a woman-controlled method that requires minimal provider counseling to ease the burden on their time and the possibility of distribution through community health workers was evident.

Across all three countries, most participants (up to $85 \%$ of women, $95 \%$ of procurers, and $100 \%$ of providers) expressed interest in the one-year Nestorone $\AA /$ Ethinyl Estradiol contraceptive vaginal ring (CVR) and even expressed a willingness to pay higher prices for the ring.

\section{WILLINGNESS TO PAY: KENYA}

The public sector remains the primary source of sexual and reproductive health care financing in Kenya, but funding shortages have prompted the exploration of new financing models to help meet the contraceptive needs of women and their families. So the private sector remains a key option for contraceptive security. As Kenya is among the most vibrant economies in East Africa (with 4.9\% economic growth reported in the first quarter of 2015), it's even more important to equip and empower women with a range of family planning services and resources to help maintain their health and support their contributions to economic growth.

While Kenya's total fertility rate (TFR) has declined significantly since the mid-1970s, the current rate remains at roughly 3.9 births per woman (3.1 and 4.5 births in urban and rural regions, respectively). And, just more than half of married women (58\%) are using a contraceptive method, although contraceptive prevalence reportedly increases substantially with higher education rates. Despite the progress made in contraceptive use, many women are still left behindespecially those who need access to a contraceptive in the first 12 months postpartum.

In this study, willingness to pay was evaluated in Nairobi County, as it has the highest concentration of urban, educated women. And, because family planning counseling is offered free of charge, the study sought to understand whether women, providers, and procurers would be receptive to paying for and obtaining the PVR, especially given the global effort to move economies toward a Total Market Approach.

Key findings from the Kenya WTP study (Liambila et al. 2015) include:

- Women reported that they would be willing to pay for the PVR if it was available to them.

- A majority who obtain services through the private commercial sector spend, on average, between 50 cents and US\$2 (50-199 Kenya shillings [KES]) each month on family planningsuggesting a market exists for the introduction of new products via the private sector.

- Most women surveyed would pay a price equal to a three-month supply of progestinonly pills, plus a $10 \%$ increase. Women who rely on the public sector for the provision of family planning services were more sensitive to marginal price increases compared with those interviewed at private-sector facilities.

- A majority noted that they would look for affordable alternatives (52\%) and go to places where the PVR might be provided free of charge (27\%) if the selling price of the PVR is too high for them.

- Providers highlighted the value of the PVR as an important addition to the contraceptive method mix, particularly in light of frequent prolonged stock-outs of other methodsincluding oral contraceptives.

Interestingly, procurers expressed willingness to make the PVR available through their networks and indicated willingness to purchase at a higher cost than what women reported. 
Taken together, these findings indicate a high level of interest in seeking, obtaining, and providing the PVR across a diverse range of stakeholders in Kenya, and underscore the value that social marketing organizations and commercial groups can play in helping ease the burden on public health expenditures.

By leveraging Kenya's growing economy and supporting cross-collaboration through the provision of family planning services, these findings accentuate a positive outlook for postpartum breastfeeding women who need access to novel, woman-controlled, discreet methods without placing a burden on already-stretched health care resources.

\section{WILLINGNESS TO PAY: NIGERIA}

In Nigeria, family planning financing was entirely donordriven until 2011 when the Federal Government of Nigeria committed to providing US $\$ 3$ million annually from 2011 to 2015 for procurement of contraceptives for the public sector. Following the London summit in 2012, the Nigerian government made a further pledge of providing an additional US $\$ 8.3$ million.

Contraceptive services and commodities are available free of charge at public health facilities in Nigeria; however, public facilities have frequent stock-outs and therefore the private sector accounts for more than $60 \%$ of provision across rural and urban settings.

Over the last two decades, Nigeria's contraceptive prevalence rate (CPR) for modern contraception has remained steadily at $10 \%$, representing one of the lowest rates in sub-Saharan Africa. However, Nigeria's Federal Ministry of Health has set an ambitious new target of raising the CPR to more than $35 \%$ by the year 2018 . One method identified to help achieve this goal is addressing the needs of postpartum women, where the need is $65 \%$ (as opposed to just above 15\% for nonpostpartum women). Further, procurement, pricing, and quality assurance systems are particularly robust in Nigeria.

In the country, providers across all three sectors indicated the importance of including the PVR in the method mix. Their responses highlighted the importance of educating potential providers to ensure their successful integration when eventually registered.

Key findings from the Nigeria analysis (Ishaku et al. 2015) include:

- $\quad$ Women, providers, and procurers unanimously expressed support for the PVR suggesting that the method could represent a welcome development and add value to the family planning landscape.

- Women were willing to pay for the PVR regardless of the sector at a price of US $\$ 1.70$ (300 Naira [N]); and, in the private commercial and nonprofit sectors, a significant portion of women noted willingness to purchase the PVR at higher prices.

- Stakeholders also expressed interest and support/willingness to try the one-year investigational CVR-a ring that, if approved by regulatory authorities, could potentially be used for up to one full year.

\section{WILLINGNESS TO PAY: SENEGAL}

With a population estimated at 13 million in 2014, Senegal continues to face a high population growth rate (approximately $2.5 \%$ ). Consequently, this growth rate contributes to a predominantly young population (more than 50\% under 18 years of age), which should lead to a higher fertility rate (births per 1,000 women of reproductive age) in the next decade. According to 2013 estimates, Senegal's total fertility rate is about 5.3 children per woman.

The desire for large families in Senegal comes from cultural beliefs that children bring life into the household and are an investment. High fertility is also related to the low use of modern contraception. Following its engagement in the Ouagadougou Declaration, the Ministry of Health launched a voluntary National Action Plan for Family Planning in 2012. The objective is to increase the Contraceptive Prevalence Rate from $12 \%$ to $27 \%$ by 2015 and $45 \%$ in 2020 .

Senegal's Dakar region-which boasts the highest population density-maintains an unmet need for family planning of $32 \%$, which has remained constant despite a higher modern CPR of $21 \%$, due in part to frequent stock-outs. According to DHS records from $2010-11,60 \%$ of women who gave birth in the two years prior to the survey reported unmet need. Among postpartum women, $66 \%$ who were breastfeeding reported unmet need versus $40 \%$ for those not breastfeeding. 
Key findings from the Senegal analysis (Mané et al. 2015) include:

- Women in the public and private nonprofit sectors were willing to pay US\$1-\$2 (5001,000 FCFA) for the PVR. And, among potential users who learned about the PVR for the first time, more than $70 \%$ expressed interest in using it-and this "willingness to try" highlights the high unmet need and opportunity for the PVR in creating value for Senegalese women.

- Of women interested, more than 85\% reported willingness to pay, even if the price rose, to avoid unintended pregnancy.

- Across all sectors, health care providers reported willingness to offer the PVR-and supported its inclusion in the country's national family planning program. Providers also supported a price as high as US\$2 per ring $(1,000$ FCFA) in the public and private nonprofit sectors, with those in the commercial private sector willing to pay more.

- Procurers were unanimously supportive of the PVR and recommended prices as high as US\$4.

\section{CONCLUSIONS AND KEY LEARNINGS}

Product introduction strategies demand rigorous market research and often rely on hypothetical approaches to gauge demand, provider interest, and procurers' ability and willingness to make new contraceptive methods available to the women who need them most. In addition to considering what price stakeholders are willing to pay, it is essential to weigh price against a stream of potential benefits-the potential health outcomes, improvements and efficiencies in the health system, and individual and societal health and economic gains. Furthermore, a pricing model defines the prices paid and benefits accrued to different stakeholders.

Clinical trial results demonstrate that the PVR is safe for both mothers and their babies, in addition to being 98.5\% effective when used correctly. Research also indicates that women may experience other health benefits from breastfeeding, such as reduced risk of ovarian and breast cancer (Sivin et al. 1995; Carr et al. 2015). As such, the PVR represents an important addition to the contraceptive method mix and product landscape for postpartum women in developing countries where resources are scarce.
With adequate planning for the introduction of a new contraceptive product, the health care sector can ensure that women are able to access the right product, in the right place, at the right time.

Sustaining an effective Total Market Approach is key to increasing family planning access and use, as well as ensuring continuation of services across public and private sectors. Central to this approach is that providers in the public and private sectors leverage their comparative advantages to reach different types of clients with appropriate products and services.

The PVR contributes to a Total Market Approach by reaching new clients who might otherwise be overlooked due to resource constraints, creating the opportunity to improve equitable access.

In addition to the PVR, the Population Council and its partners are continuing development of a oneyear, long-acting, reversible contraceptive vaginal ring (CVR) containing two hormones that, if approved by regulatory agencies, could be used by nonbreastfeeding women. In each study, participants were asked if they would be interested in this method as an alternative to other long-acting methods (e.g., IUDs), because the CVR is also designed to be woman-controlled and would offer a comparable level of discretion. Women across all three countries expressed interest and willingness to pay for this product.

Willingness to pay and the price paid by different stakeholders are important considerations in the initial stages of introduction of a new contraceptive. As the market matures for the contraceptive, the potential for price reductions emerges. Efficiencies in manufacturing and distribution to meet increased demand can lower prices, as can the entry of new manufacturers. With the overall contraceptive market poised to grow in the next two decades to meet the needs of a growing population, the dynamics of supply and demand will significantly alter the initial price offering.

\section{REFERENCES}

Carr, S.L. et al. 2016. "Safety of the progesterone-releasing vaginal ring (PVR) among lactating women: A systematic review," Contraception 94(3): 253-261. (E-pub, ahead of print, 11 April.)

Evidence Project. 2014. "Strengthening a Total Market Approach." http://evidenceproject.popcouncil.org/strengthening-a-total-marketapproach-case-studies. Accessed 11 September 2016. 
Ishaku, S. et al. 2015. "Willingness to Pay for Contraceptive Vaginal Rings in Nigeria." http://www.popcouncil.org/uploads/pdfs/

2015RH_WillingnessToPayCVRNigeria.pdf. Accessed 11 September 2016. Nigeria: Population Council

Liambila, W. et al. 2015. The Population Council. "Willingness to Pay for Contraceptive Vaginal Rings in Kenya."

http://www.popcouncil.org/uploads/pdfs/2015RH_

WillingnessToPayCVRKenya.pdf. Accessed 11 September 2016.

New York: Population Council.

Mané, B. et al. 2015. "Willingness to Pay for Contraceptive Vaginal Rings in Senegal." http://www.popcouncil.org/uploads/pdfs/ 2015RH_WillingnessToPayCVRSenegal.pdf. Accessed 11

September 2016. Dakar: Population Council.

Obare, F. et al. 2014. "Assessing the Potential Market for a Progesterone Contraceptive Vaginal Ring (PCVR) as a New Contraceptive Option in sub-Saharan Africa Using Needs-Based Market Segmentation." http://www.popcouncil.org/uploads/pdfs/ 2014RH_MarketSegmentReport-PCVR.pdf. Accessed 11 September 2016. New York: Population Council.

Sivin, I. et al. 1997. "Contraceptives for lactating women: A comparative trial of a progesterone-releasing vaginal ring and the copper T 380A IUD," Contraception 55(4): 225-232.

Suggested citation: Population council. 2016. "Introducing the Progesterone Contraceptive Vaginal Ring in sub-Saharan Africa." New York: Population Council.

This publication is made possible by the generous support of the American people through the United States Agency for International Development (USAID). The contents are the responsibility of the Population Council and do not necessarily reflect the views of USAID or the United States Government. 